\title{
Biomimetic Preparation of Hybrid Porous Adsorbents for Efficiently Purifying Complex Wastewater
}

Hongmin Wang, $†$ Chan Wang, $\neq$ Shengyang Tao, $* *$ Jieshan Qiu, $\perp$ Yongxian Yu and Minfen Gu //

AUTHOR ADDRESS

Shengyang Tao* E-mail: taosy@dlut.edu.cn

$\dagger$.Department of Chemistry, Dalian University of Technology, Dalian 116024, Liaoning, P.R. China.

$\$$ Chinese Academy of Sciences, Yantai Shandong Center for Integrated Technology Transfer Center, Shandong, China.

$\perp$. Carbon Research Laboratory, Liaoning Key Lab for Energy Materials and Chemical Engineering, State Key Lab of Fine Chemicals, School of Chemical Engineering, Dalian University of Technology, Dalian 116024, Liaoning, P.R. China.

//. Center of Analysis and Testing, Nanjing Normal University, 1 Wenyuan Road, Nanjing, Jiangsu. 


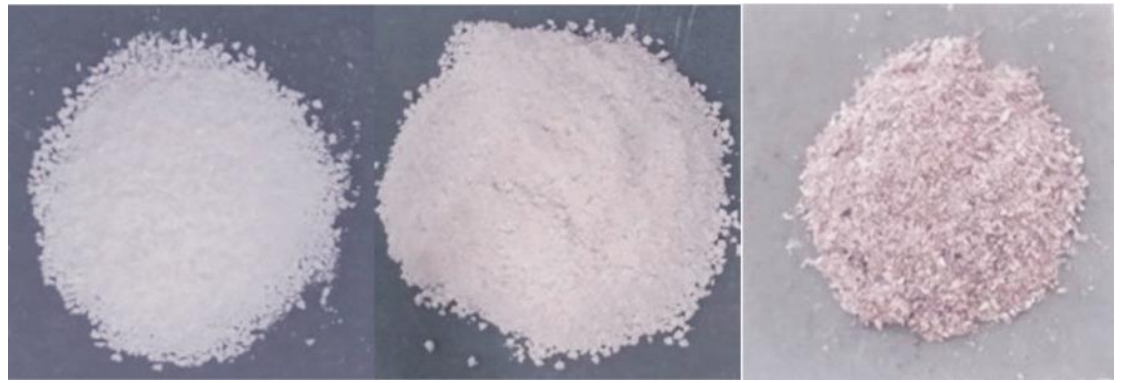

Figure S1. photograph of HPS(left), photograph of HPS/PG(middle), photograph of Au/HPS/PG 


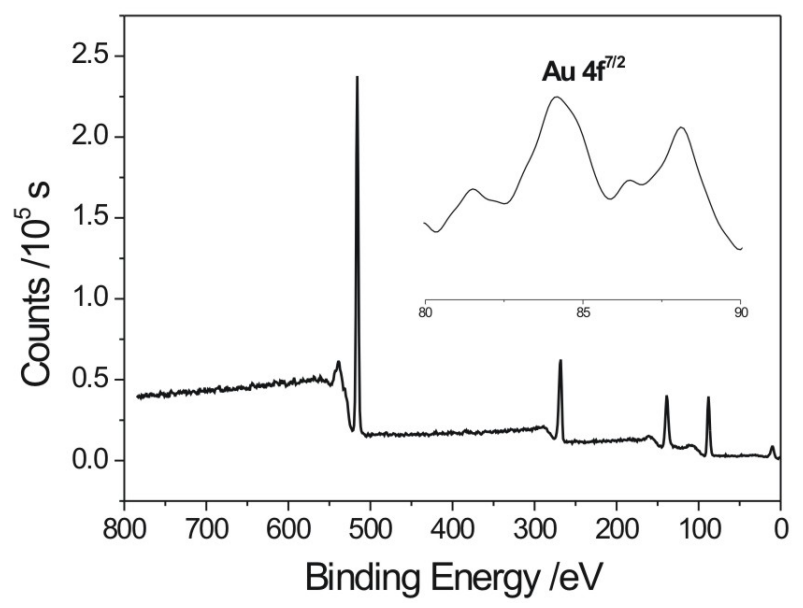

Figure S2. XPS patterns of Au/HPS/PG 
Table S1 Isotherm constants of HPS for the adsorption of pollutants

\begin{tabular}{llll}
\hline & \multicolumn{3}{c}{ Langmuir isotherm } \\
\cline { 2 - 4 } dyes & $\mathrm{Q} / \mathrm{mg} \mathrm{g}^{-1}$ & $\mathrm{~B} / \mathrm{L} \mathrm{mg}^{-1}$ & $\mathrm{R}$ \\
\hline Fuchsin basic & 180.3 & 0.04 & 0.992 \\
Rhodamine B & 111.1 & 0.03 & 0.980 \\
$\mathrm{~Pb}^{2+}$ & 83.0 & 0.02 & 0.995 \\
$\mathrm{Hg}^{2+}$ & 53.97 & 0.02 & 0.990 \\
\hline
\end{tabular}




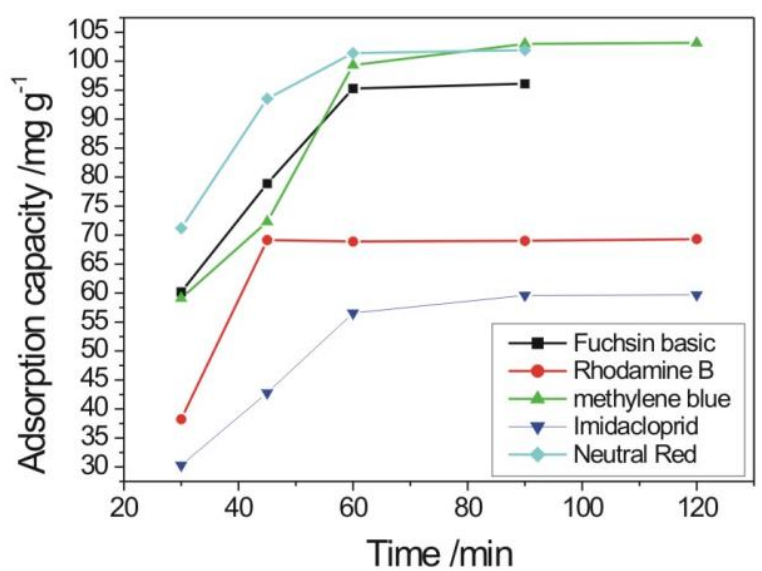

Figure S3. Effect of contact time on the adsorption of basic dyes $\left(50 \mathrm{mg} \mathrm{L}^{-1}\right)$ onto HPS/PG 


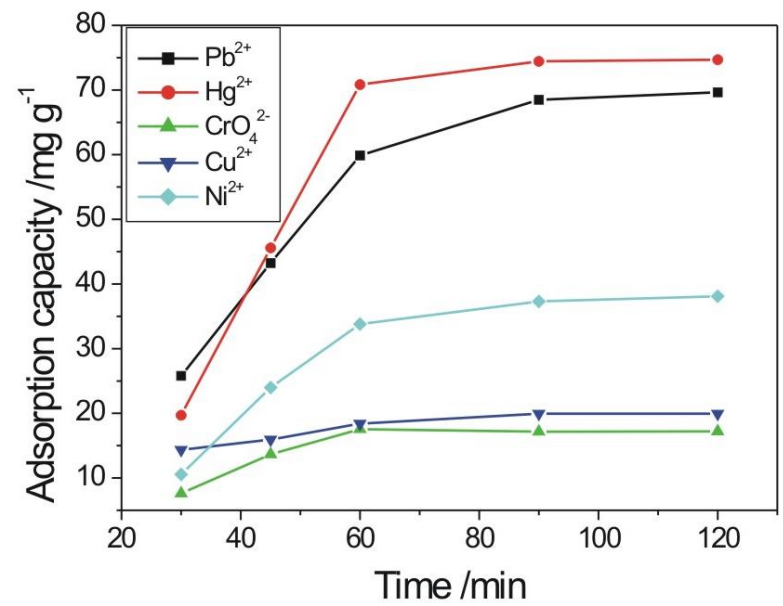

Figure S4. Effect of contact time on the adsorption of metal ions $\left(30 \mathrm{mg} \mathrm{L}^{-1}\right)$ onto HPS/PG 
Table S2 Comparison of HPS/PG-N (PG new-coating HPS) and HPS/PG-T (PG-coating HPS three months) to purify neutral red.

\begin{tabular}{ccc}
$\begin{array}{c}\text { Removal \% of } \\
\text { material }\end{array}$ & $\begin{array}{c}\text { The concentration before } \\
\text { adsorption }\left(\mathbf{m g ~ L}^{\mathbf{- 1}}\right)\end{array}$ & $\begin{array}{c}\text { The concentration after } \\
\text { adsorption }\left(\mathbf{m g ~ L}^{\mathbf{- 1}}\right)\end{array}$ \\
\hline HPS/PG-N & 22.06 & 12.58 \\
\hline HPS/PG-T & 22.06 & 13.02 \\
\hline
\end{tabular}

